\title{
Guerra fiscal na federação brasileira: a contribuição das abordagens da sociologia econômica
}

Alguns temas de natureza econômica adquiriram um protagonismo também em áreas como as ciências sociais, particularmente a ciência política e a sociologia econômica. Objetivamos com este estudo ressaltar o papel da sociologia econômica para articular algumas fontes analíticas para temas recorrentemente presentes nas agendas governamentais, utilizando-nos, neste sentido, como cerne de nosso estudo, o fenômeno da guerra fiscal. Portanto, objetivamos discorrer sobre a guerra fiscal não como fenômeno autônomo, pertencente à esfera econômica, mas como produto de interações sociológicas e políticas por parte dos atores sociais, tais como os governadores de estado. Para tanto, utilizamos uma bibliografia de fonte secundária situada em disciplinas como a economia, a sociologia econômica e a ciência política.

Palavras-chave: sociologia econômica, ciência política, guerra fiscal.

\author{
* Doutora e mestre \\ em ciência política \\ pela Universidade \\ Federal de São \\ Carlos, professora \\ do curso de \\ administração \\ pública da \\ Universidade \\ Estadual Paulista \\ Júlio de Mesquita \\ Filho (Unesp- \\ Araraquara). \\ <leiacolombo@ \\ gmail.com>.
}

\section{Introdução}

O objetivo principal deste estudo é estabelecer um diálogo sobre os pressupostos da sociologia econômica, questionando a primazia que a economia se apoderou, durante muitos anos, sobre outras áreas do conhecimento, sobretudo porque ocupou espaços onde as ciências sociais deveriam, por seu próprio núcleo estruturador, atuar. Corroboramos a assertiva de que fenômenos aparentemente apenas econômicos têm implicações mais gerais, os quais poderiam e deveriam ser estudados por outras ciências, como a ciência política ou a sociologia econômica, por exemplo. A partir de tais considerações, utilizamos o exemplo da guerra fiscal, prática recorrente na federação brasileira, que, apesar de apresentar uma natureza fiscal - portanto, aparentemente estrita à área econômica -, envolve uma série de fatores não econômicos, principalmente em medidas que visam justamente sua extinção.

Realizadas tais considerações, este artigo é dividido da seguinte maneira: nesta introdução, abordaremos as origens da sociologia econômica, bem como seus principais expoentes; em uma segunda parte, abordaremos os pressupostos desenvolvidos por autores como Max Weber e Mark Granovetter e como eles se posicionam acerca da ciência econômica e a maneira como estes autores analisam o envolvimento entre as 
esferas da política e do Estado; em um terceiro momento, abordaremos as causas da guerra fiscal e suas principais repercussões na federação como um todo; finalmente, nas conclusões, salientaremos a importância de uma interdisciplinaridade para a compreensão de determinadas práticas usualmente caracterizadas como econômicas.

Este trabalho justifica-se sobretudo porque a análise interdisciplinar envolvendo áreas de conhecimento como a economia e as ciências sociais em geral - notadamente a ciência política - aumentou consideravelmente nos últimos anos; neste sentido, as contribuições de cada ciência passaram a se mesclar umas com as outras, obtendo, assim, visões mais amplas sobre os diferentes assuntos. Neste sentido, a sociologia econômica também surgiu fortemente alicerçada sobre importantes pilares teóricos e se consolidou principalmente a partir da década de 1990. Nas palavras de Oliver Williamson:

\footnotetext{
As abordagens econômica e sociológica da organização econômica alcançaram um estado de tensão salutar, em contraste com o estado de coisas anterior, em que as duas se ignoravam e até mesmo chegavam a descrever as agendas e as conquistas de pesquisa umas das outras com desprezo (Williamson, 1994: 77).
}

Além disso, durante muitos anos o então denominado "imperialismo econômico", exclusividade das ciências econômicas, procurava abarcar parte do conjunto das ciências sociais, e se autodefinia pelos pressupostos do comportamento racional e maximizador de interesses, visando atingir o equilíbrio de mercado e a estabilidade de preferências, com redução dos custos de transação - elementos decisivos nas análises pertinentes (Abramovay, 2004). O próprio Pierre Bourdieu, em um de seus últimos trabalhos, assevera:

A ciência que se chama economia repousa sobre uma abstração
originária, que consiste em dissociar uma categoria particular de
práticas, ou uma dimensão particular de toda prática, da ordem so-
cial na qual toda prática humana está imersa (Bourdieu, 2000: 11).

A noção de economia como esfera autônoma do conhecimento era amparada por pensadores clássicos, como John Stuart Mill, cujo argumento principal reside no fato de que a economia emprega o método dedutivo, cujo postulado permite a compreensão da preferência humana através da qual os indivíduos sempre optarão por uma quantidade de riqueza maior, em detrimento de uma quantidade menor. Era uma noção, portanto, de que a economia era uma ciência completa, que não necessitava de outras contribuições teóricas, voltadas, por exemplo, ao estudo do comportamento holístico do homem e da sociedade. 
A primazia deste "imperialismo econômico" sobre as demais ciências não teve uma trajetória muito abrangente, pois os primeiros trabalhos de Bourdieu impactaram decisivamente, especialmente através do conceito básico de habitus, o qual passou a ser amplamente divulgado nas escolas de sociologia, com destaque para as instituições norte-americanas. Desta forma, as primeiras teorias opostas à teoria econômica ortodoxa começaram a surgir no início dos anos 1980, nos Estados Unidos, questionando vários postulados econômicos neoclássicos. Assim se originava a chamada nova sociologia econômica, a qual passava a caracterizar os mercados como formas de coordenação social caracterizada por conflitos, dependências, estruturas complexas e elevadas imprevisibilidades, diferentemente dos pressupostos rígidos e fixos existentes na teoria econômica até aquele momento. A então denominada nova sociologia econômica teria o mérito principal de analisar sociologicamente o núcleo duro da ciência econômica, ou seja, o mercado, considerando-o como "estrutura social" (Swedberg, 1998).

Como ressalta Ricardo Abramovay (2004) - ao resgatar o pensamento de David Dequech -, as ciências sociais vivenciaram uma espécie de "virada cognitiva", a qual buscava questionar o núcleo duro da ciência econômica, responsável pela condução de análises que menosprezavam comportamentos orientados por princípios históricos e sociais.

\begin{abstract}
A sociologia econômica contemporânea tem justamente essa característica de conceber os mercados como resultados de formas específicas, enraizadas, socialmente determinadas de interação social, e não como premissas cujo estudo pode ser feito de maneira estritamente dedutiva (Abramovay, 2004: 7).
\end{abstract}

Granovetter foi um dos autores pioneiros desta nova sociologia econômica e, em artigo de 1985 - "Economic action and social structure: the problem of embeddedness" -, passou a definir e a analisar os mercados como arenas privilegiadas de redes interpessoais. A partir do conceito de "rede" e de embeddedness (enraizamento), Granovetter promoveu uma inovação importante no campo da sociologia econômica, noções sobre as quais diversos pesquisadores também se debruçaram posteriormente. Além de considerar a existência do homo economicus, Granovetter ampliou os pressupostos básicos do comportamento do ator econômico, acrescentando em suas análises também elementos das motivações não econômicas (Swedberg, 1998; Granovetter, 1992). A argumentação nuclear do pensamento de Granovetter está em sua observação de a ação econômica ser uma forma de ação social, de a ação econômica estar socialmente situada, bem como de as instituições econômicas também serem construções sociais e não meramente econômicas e financeiras (Raud-Mattedi, 2005a). 
1. Granovetter distingue dois tipos de enraizamento: o relacional e o estrutural. 0 primeiro diz respeito às relações pessoais mais próximas ao indivíduo: família, escola, amigos, etc.; o segundo refere-se a relações mais distantes, às quais o indivíduo mantém relações através dos chamados laços fortes - mantidos através de parentes e amigos próximos - e também dos laços fracos mantidos através de conhecidos - os quais o colocam em contato com diferentes ambientes sociais, adquirindo influência destes ambientes.
Neste sentido - a seguir a argumentação desenvolvida por Granovetter -, se a ação econômica é uma forma de ação social, então os atores perseguem, além dos objetivos econômicos, objetivos sociais, como a sociabilidade, o reconhecimento, o poder. Além disso, a prerrogativa da ação econômica socialmente situada também conduz ao entendimento de que os indivíduos não agem de maneira autônoma, mas que suas ações estão enraizadas, fixadas em sistemas concretos e complexos de relações sociais, ou seja, em redes sociais: eis então a tese do embeddeness ${ }^{1}$, ou enraizamento social das ações econômicas. Uma vez que as ações dos atores sociais são condicionadas por seu pertencimento a redes de relações interpessoais, capazes de alterar comportamentos, então o mercado não se caracteriza somente como um jogo de forças abstratas, mas também como um complexo jogo entre atores sociais diversos que operam um conjunto de ações estreitamente enraizadas em redes de relações sociais.

Cabe ressaltar que a análise de rede de Granovetter (1994) leva em conta as "interações concretas entre indivíduos e grupos", cujo cerne das redes é configurado para facilitar a circulação de informações e aumentar a confiança dos indivíduos ao exercer mecanismos que inibem comportamentos oportunistas e individualistas. Assim, as relações econômicas são travadas em ambientes que detêm uma rede de indivíduos que se conhecem diretamente, ou que irão se reconhecer por intermédio dos indivíduos pertencentes à mesma rede social. E devemos nos perguntar, então: se as redes são o meio e o fim das relações econômicas e sociais, qual o papel das instituições? As relações entre os atores econômicos necessitam da intermediação de uma instância que regule tais relações: aí reside a importância das instituições, que são relevantes porque as regras importam; e as regras importam porque os incentivos importam para manter o próprio funcionamento das redes (Raud-Mattedi, 2005a).

Ao lado de Mark Granovetter (1994), Douglass North (1994) também teorizou sobre a importância das instituições, e sua exposição dos diálogos entre institucionalistas econômicos e sociológicos é bem interessantes. North (1994) advoga que uma das maiores virtudes das instituições é sua capacidade de reduzir os custos de transação; a vida social é delineada pelo autor como obscura em função da dificuldade de os atores entenderem as premissas e os pontos de vista a partir dos quais os outros agem para que todos tenham como parâmetro de confiança a previsibilidade, modeladora das relações. Em sua visão, uma instituição caracteriza-se pela capacidade de implementação de decisões; além disso, elas reduzem o grau de incerteza, característico dos comportamentos imprevisíveis dos atores, e ao propiciar previsibilidade, as instituições permitem aos atores que dela participam uma facilidade na identificação de parceiros adequados para a elaboração de um contrato. As 
instituições são capazes de resolver também problemas de ação coletiva, trazendo à tona contribuições de indivíduos que necessitam da coordenação e de mecanismos externos que Ihe garantam previsibilidade para agirem conjuntamente (Levi, 1991).

A partir da dedução de que as instituições reduzem os custos de transação, North (1994) dedicou sua atenção ao que envolveria os pressupostos dos custos de transação. Concluiu que tais custos não envolvem apenas um problema de informação nem sempre completa, mas abarca todo um sistema de crenças que determina a ação social. A ênfase de North neste sistema de crenças foi, em grande medida, inspirada em Max Weber (1991), que desenvolveu sua análise sociológica baseado no estudo do sentido da ação social, ou seja, a interiorização de teorias, ideologias e representações sobre o mundo.

Já para Granovetter (1994), a definição de instituições é mais extensa, visto que abrangeria desde os sistemas de organização, como o capitalismo, até a forma das organizações das indústrias e dos grupos profissionais particulares. Mas o cerne da definição de instituições para o autor está na assertiva que instituições são construções sociais.

As instituições econômicas estáveis começam por se desenvolver na base de modelos de atividade construídos ao redor de redes pessoais. Sua estrutura reflete a das redes em questão (Granovetter, 1994: 91).

Além da preocupação com a definição de instituição, o autor retoma, então, a ideia de path dependency (dependência de trajetória) e questiona por que alguns países, com instituições semelhantes, conhecem um crescimento econômico baseado na criação de grandes empresas e outros permanecem estagnados, mesmo adotando medidas políticas e econômicas análogas:

Mesmo se as condições econômicas e políticas são idênticas, a forma final pode variar completamente se as estruturas sociais são diferentes. Quando as estruturas de mercado parecem exigir a emergência das empresas, elas podem, no entanto, não nascer se elas não se apoiam numa estrutura social de grupo (Granovetter, 1994: 91).

Com base nesta constatação de Granovetter, há uma explicação também para o desenvolvimento desigual, dentro de um mesmo território, em um mesmo país, ou, ainda, em uma mesma região, onde membros de um mesmo grupo social podem apresentar resultados econômicos diversos, pois estão imersos em estruturas sociais diferenciadas. A análise de Granovetter se estende, ainda, para o âmbito privado, onde as estruturas sociais são capazes de moldar as empresas, que também 
apresentam dependência das redes sociais estabelecidas (Raud-Mattedi, 2005a). A tese de Granovetter (1994) pode ser transposta para o caso brasileiro, cujo federalismo apresenta grandes desigualdades regionais, especialmente com as regiões Norte e Nordeste destoando das demais, apresentando níveis de desigualdade econômica bastante significativos. Uma das explicações para a permanência de tais desigualdades tem origem na ausência de uma política consistente de desenvolvimento, transformando-se em lacuna deixada pelo Estado, suprida por mecanismos deletérios, como a guerra fiscal, que passam ser recorrentes na federação, como será evidenciado nas seções subsequentes.

Observa-se, até o exposto, avanços importantes obtidos no campo da sociologia econômica em relação a temas anteriormente desenvolvidos tão somente pela ciência econômica. A partir da análise de rede de Granovetter, por exemplo, pode-se trazer respostas para problemas-chave da teoria econômica, como, por exemplo, o mercado de trabalho, o desenvolvimento econômico e social, a transformação das empresas e dos grupos econômicos que dela fazem parte, ou ainda o sistema financeiro, pautado por critérios de confiança.

\section{A contribuição da sociologia econômica para o debate}

Uma das grandes contribuições da sociologia econômica reside no fato de que a ação econômica é uma ação social e por essa característica, subordina-se a diversos fatores não econômicos; além disso, há uma ausência de autonomia que envolve as ações econômicas, preceitos que não agradam aos apreciadores do então denominado "imperialismo econômico", que disseminavam a idealização da ciência econômica como um fim em si, área do conhecimento desprovido de afinidade com as demais ciências. Weber (1991), quando analisa o mercado - em Economia e sociedade-, questiona tanto a presença deste homo economicus quanto a primazia do mercado econômico como esfera individual:

Quando o mercado é deixado à sua legalidade intrínseca, leva apenas em consideração as coisas, não a pessoa, inexistindo para eles deveres de fraternidade e devoção ou qualquer das relações humanas originárias sustentadas pelas comunidades pessoais. 0 mercado, em contraposição a todas as demais relações comunitárias que sempre pressupõem a confraternização pessoal e, na maioria das vezes, a consanguinidade, é estranho, já na raiz, a toda confraternização (Weber, 1991: 420).

Abramovay (2004) vai ao encontro dos argumentos de Weber e ressalta que não se trata de desmistificar o mercado como um mecanismo autorregulável, mas de 
inserir nas análises dos mercados os vínculos sociais concretos, os quais oferecem subsídios importantes para a compreensão das dinâmicas dos mercados, na qual a autorregulação depende da própria maneira como a interação social ocorre. A especificidade da impessoalidade dos mercados não impede que eles sejam construídos e organizados mediante formas concretas de coordenação, cujo estudo empírico é o objeto da nova sociologia econômica.

Com o intuito de estabelecer parâmetros de análise, delimitando o campo de atuação desta sociologia econômica, Swedberg (1998) retoma os estudos de Weber, estabelecendo limites entre as atuações da sociologia e da economia. Para Swedberg (1998), a unidade básica da sociologia é o indivíduo, movido por seus interesses pessoais. A distinção entre a sociologia e a teoria econômica situa-se exatamente no enfoque sobre a ação social deste indivíduo. A análise da ação social é um ponto central na análise de Weber:

Action is social only insofar as its subjective meaning takes account of the behavior of others and is thereby oriented in its course (Swedberg, 1998: 57).

A oposição entre as ciências ocorre na delimitação do próprio objeto de estudo: enquanto a teoria econômica analisa a ação econômica em sua generalidade, a sociologia enfatiza o significado do comportamento e da interação social dos indivíduos. Esta distinção é crucial para a fundamentação da tipologia da ação social de Weber.

O mais atraente na teoria weberiana é a reflexão conjunta sobre os pressupostos do imperialismo do econômico que sofrem uma justaposição das noções individualizadas e egoístas dos agentes sociais. Há uma substituição na análise weberiana do homo economicus pelo homo sociologicus, onde este último é fruto dos recortes analíticos do indivíduo atomizado, cuja característica singular é o fato de suas decisões se pautarem pelo sentido que ele atribui a elas e também às ações dos outros. O conjunto de características do "homem sociológico" é dividido em partes analíticas bem delimitadas: impulsos econômicos, religiosos, políticos ou ideológicos, que moldam o comportamento dos indivíduos e os motivam a agirem não mais de maneira unilateral, mas considerando a complexidade das ações humanas.

Neste sentido e seguindo a linha de raciocínio aqui desenvolvida, a coletividade não é para Weber (1978) algo que existe por si só, mas é também um objeto em constante construção e reconstrução. As estruturas e as instituições são realidades concretas produzidas pelos homens, os quais, ao se sentirem representados, conferem legitimidade a elas. A ação coletiva adquire legitimidade a partir dos significa- 
dos atribuídos pelos comportamentos individuais, ressaltando-se a particularidade de que essa perspectiva metodológica centrada no indivíduo não implica compromissos com sistemas individualistas de valores. Elisa Reis (1998) é uma das autoras que analisou profundamente a interferência do homo sociologicus, de forma a relativizar a presença do homo economicus. Ao partir de uma comparação entre Weber e Durkheim, a autora em tela reforça que explicações sociológicas assentam-se na possibilidade de reconhecer ações individualizantes fundamentadas em uma narrativa compreensiva. A autora retoma os pressupostos weberianos, os quais salientam que mesmo que estivéssemos sob os auspícios de uma economia socialista, ainda assim teríamos de utilizar instrumentais analíticos que priorizassem os elementos sociológicos em termos individualistas, ou seja, da ação dos indivíduos atuantes nesta economia; de forma similar, uma economia caracterizada pelo livre-mercado também teria elementos semelhantes ao priorizar, por exemplo, a teoria marginal.

Um questionamento nuclear seria então: qual é a percepção de Weber sobre a relação entre economia e política? Ao se considerar as definições usuais da sociologia econômica, acima empregadas, qual é o papel do Estado segundo essas mesmas teorias?

Weber (1991) considerava a influência da esfera política sobre a econômica, nas palavras de Swedberg, nos seguintes termos:

The economy may influence society, but, then again, noneconomic phenomena may equally well influence the economy. In addition, he said, economic phenomena may influence society, but not necessarily in a decisive manner (Swedberg, 1998: 53).

Além disso, a eliminação do Estado nas análises do fenômeno econômico pode ser apropriada em teoria econômica, mas não em sociologia econômica (Weber, 1991). Quando analisa o papel do Estado, Weber considera o conceito de "luta", o qual aparece como ponto central na análise weberiana tanto no campo da sociologia política quanto no da sociologia econômica. O conceito básico que diferencia tais campos é a violência, cujo monopólio é do Estado, sendo a atividade econômica considerada uma atividade pacífica, onde os conflitos de interesse são resolvidos pelo compromisso ou pelo poder, mas sem o uso da violência (Swedberg, 1998). Definidas as proporções entre as áreas de atuação, a ordem econômica é para Weber

2. Raud-Mattedi também compactua em seus artigos destes pressupostos weberianos.
(1978) garantida pela ordem política: "Atrás de toda economia existe um elemento coercivo - atualmente manejado pelo Estado" (Weber, 1978: 10)².

Neste sentido, segundo Weber (1991), toda relação econômica de mercado estaria condicionada a uma intervenção direta do Estado. Assim como o direito, o papel 
do Estado para Weber é assegurar a estabilidade das regras do jogo, garantindo a manutenção de um ambiente econômico com estabilidade, previsibilidade e confiança aos jogadores. Além disso, a função do Estado em uma perspectiva weberiana é garantir a existência de um sistema monetário racional, impedindo que haja interesses políticos pautando a agenda econômica e as oscilações da moeda (Raud-Mattedi, 2005b).

Além do papel do Estado, Weber aponta suas considerações sobre o mercado. Para o autor, a dominação de tipo legal é, das três formas de dominação, a mais adequada à economia de mercado, considerada a lógica da função da burocracia, com regras claras, impessoais e sem arbitrariedade. Neste tipo ideal racional-burocrático, o ator econômico tende a orientar sua ação em função do comportamento dos outros atores, os quais necessitam ser minimamente previsíveis, gerando confiança nas trocas estabelecidas. O ator econômico priorizado por Weber não se comporta de maneira autônoma, mas baseia seus comportamentos subjetivos em interconexão com outros comportamentos tipificados e transmitidos através das instituições.

Contribuições como a de Weber e Granovetter contribuíram para ampliar o campo da sociologia econômica; desmistificaram alguns pressupostos econômicos clássicos, pela via da valorização da sociologia e dos comportamentos coletivos e sociais. Nas palavras de Ricardo Abramovay:

Uma das mais importantes tarefas nas ciências sociais contemporâneas é estabelecer programas conjuntos de pesquisa que ultrapassem fronteiras disciplinares muitas vezes artificiais (Abramovay, 2004: 16).

Inspirados por tal pensamento, no tópico seguinte procuraremos expor as principais razões que cercam hoje o tema da guerra fiscal, procurando inferir a este fenômeno além do simples fator econômico que o envolve, motivações de ordem política e sociológica.

A guerra fiscal na federação brasileira: um fator econômico ou o produto de interações sociológicas e políticas?

O federalismo brasileiro distingue-se em demasia das definições que procuram conceituá-lo como sistema capaz de articular as diferenças existentes em um território, garantindo a unidade na diversidade, acomodando e resolvendo os conflitos inerentes a toda a sociedade, mas que porventura podem acarretar danos às unidades 
3. A fim de evitar confusões de ordem linguística, empregamos o termo estado (em minúsculo) para nos referirmos aos estados que compõem a federação brasileira e Estados (com letra maiúscula) para nos referirmos ao poder do Estado, ou seja, ao governo federal ao Brasil como um todo. federadas, quais sejam a União, os estados ${ }^{3}$ e, no caso brasileiro, os municípios. O sistema federal representa um arranjo institucional capaz de organizar elementos ora cooperativos, ora competitivos, e nesta ambiguidade de tarefas consegue equacionar a natureza paradoxal que envolve o relacionamento entre os entes federados. No entanto, o caso brasileiro tem a peculiaridade de justapor os elementos competitivos aos colaborativos, e cujo produto deste tortuoso relacionamento competitivo é a guerra fiscal, travada entre os estados e os municípios para a atração de investimentos e quase sempre de forma deletéria.

A Constituição de 1988 foi um divisor de águas e representou o desmonte do antigo modelo autoritário centralizador que caracterizou o período do regime militar autocrático, provocou diversas transformações na sociedade brasileira, tanto do ponto de vista da democracia, com o fim da coibição de manifestações e dos direitos fundamentais, como também promoveu alterações na própria administração pública e no aparato do Estado. Portanto, o novo formato institucional que se instalava a partir da redemocratização buscava rearticular o pacto federativo, de modo a redistribuir recursos e poder, centralizados no regime de outrora.

Uma série de debates foi realizado entre alguns teóricos sobre a matéria; como resultado da discussão, alguns entes saíram vencedores, outros perdedores, com o novo formato inaugurado pela Carta de 1988. No entanto, a versão de que os estados e municípios saíram vencedores de todo este processo parece ser condizente com a realidade atual, mas, a longo prazo, surgiu sua face negativa, notadamente com a atuação do novo sistema tributário. A inovação trazida pela Constituição de 1988 para os entes subnacionais reside no fato de os estados poderem usar sua autoridade para fixar autonomamente as porcentagens do Imposto de Circulação de Mercadorias e Serviços (ICMS), o qual constitui a base da receita estadual. A partir de tal prerrogativa dos estados, preparava-se todo o arcabouço para a contenda fiscal.

Além disso, as novas políticas internacionais provocaram uma mudança do perfil de atuação do Estado na economia, até mesmo com o fechamento de agências incumbidas da promoção do desenvolvimento regional: decretava-se o fechamento das superintendências de desenvolvimento das regiões economicamente mais fragilizadas, como a Superintendência do Desenvolvimento do Nordeste (Sudene) e a Superintendência do Desenvolvimento da Amazônia (Sudam). Todas essas alterações trouxeram repercussões imediatas para o conjunto da federação:

Na prática, a progressiva retirada do governo federal das ações discricionárias não levou à saudável hegemonia do mercado, como muitos esperavam, mas criou um vazio de políticas rapidamente preenchido pela ação dos grupos regionais (Prado \& Cavalcanti, 1998: 113). 
A extinção da Sudene e da Sudam abriu caminho para que a guerra fiscal se tornasse prática corriqueira, a partir da constatação de que o Brasil convive com dois blocos regionais formados, de um lado, por regiões desenvolvidas como o Sul, o Sudeste e parte do Centro-Oeste e, de outro, por regiões com grandes dificuldades para a promoção do desenvolvimento, como o Norte e o Nordeste. A guerra fiscal é o argumento utilizado para a atração de indústrias, mas, na maioria das vezes, agrava este quadro de desigualdades.

Concomitantemente a todo o processo descrito, a economia brasileira abria-se à iniciativa de grandes grupos econômicos internacionais e consolidava sua inserção global:

\begin{abstract}
A abertura ensejou a condição econômica para a escalada da guerra fiscal, na medida em que atraiu o fluxo crescente de capitais internacionais em busca de oportunidades de investimento no país. Parcela relevante da guerra fiscal tem a ver com a disputa por projetos industriais de origem externa, sendo os mais visíveis os da indústria automobilística (Dulci, 2002: 3).
\end{abstract}

Portanto, a guerra fiscal se fortaleceu no gargalo provocado pelo próprio Estado, na ausência de instituições adequadas para fomentar o desenvolvimento regional, contornando as desigualdades intrínsecas à federação brasileira; em contrapartida, os estados, deixados à mercê de suas próprias decisões, promoveram concessões às empresas multinacionais, com uma série de incentivos fiscais, cujo produto desta prática é uma penalização para os empreendimentos nacionais. Se, por um lado, as empresas estrangeiras são as grandes beneficiadoras da guerra fiscal, os empresários nacionais queixam-se frequentemente da carga tributária que agrava a sua produção. Os incentivos fiscais não têm, neste sentido, uma ação pulverizadora: são concentrados em empresas específicas, causando, com isso, um descontrole do setor produtivo.

O mecanismo da "guerra fiscal" permite que os estados façam uma projeção de parte das receitas de seus impostos, concedendo benefícios geralmente concentrados no setor de infraestrutura, cedendo às exigências feitas pelas empresas internacionais para se instalarem nos territórios, tornando-se, assim, reféns dessas empresas; o retorno para este tipo de concessão é difuso, pois existe uma possibilidade real de as empresas instaladas alterarem o planejamento, transferindo-se para outras regiões, onde os incentivos podem ser ainda maiores.

A guerra fiscal acaba por alterar os princípios federativos de colaboração, como adverte Eli Diniz: 
Nessa guerra, ganham os estados mais desenvolvidos, com meIhores condições locacionais e maior cacife financeiro e político. Isto, seguramente, agravará as desigualdades regionais (Diniz, 2000: 343).

Ricardo Carvalho argumenta que essa prerrogativa é um dispositivo importante para contrabalançar a ausência do Estado no fomento de políticas nacionais de desenvolvimento regional.

A ausência de política regional federal retirou das negociações entre os governos federal e estaduais o principal ponto de discussão, fazendo com que os estados percebessem que não teriam ajuda federal e deveriam conseguir por conta própria novos investimentos (Carvalho, 2001: 168).

O setor industrial foi um dos mais disputados nas contendas fiscais entre os estados, e o setor automotivo ganhou visibilidade, pois os benefícios estaduais concedidos foram inúmeros, principalmente a partir da segunda metade dos anos 1990. Segundo Glauco Arbix, os incentivos oferecidos pelo estado às empresas montadoras são geralmente os seguintes:

1. Doação de terrenos para a instalação da planta ou de grande parte dela.

2. Fornecimento da infraestrutura necessária para a preparação da área. Isso inclui, em geral, a infraestrutura viária e logística, mas abrange também, em vários casos, ligações ferroviárias e desenvolvimento de terminais portuários.

3. Isenção de impostos estaduais e locais por períodos não inferiores a dez anos. O mesmo vale para as taxas locais. Em vários casos, o acordo inclui a isenção de impostos na importação de peças e veículos.

4. Concessão de empréstimos pelo Estado (por meio de órgãos ou bancos estatais) a taxas muito inferiores às do mercado.

5. Uma série de cauções e garantias estatais, financeiras e legais.

6. Uma série de benefícios adicionais, que variam de acordo para acordo, envolvendo desde fornecimento de transporte público aos trabalhadores e creches para seus filhos a diversas medidas ambientais (Arbix, 2002: 4).

No entanto, ao permitir tais incentivos às empresas, em determinados casos o estado não tem condições de promover tantos privilégios às empresas, mas o fazem, temerários da perda do investimento. Como ressalta Ricardo Varsano, muitas vezes 
o déficit fiscal atual do Brasil ocorre, em grande medida, devido ao desequilíbrio das contas públicas estaduais:

\begin{abstract}
Em diversos estados, a arrecadação é quase que insuficiente para cobrir exclusivamente os gastos com pessoal. Mesmo entre estes, há os que insistem em participar de verdadeiros leilões promovidos pelas empresas que já decidiram instalar novos estabelecimentos no país (Varsano, 1997: 11).
\end{abstract}

Outros setores também praticam guerra fiscal, como o setor alimentício - analisado por Dulci (2002) -, que estudou as indústrias de laticínios de Minas Gerais, como a Parmalat, a Itambé e a Cotochès, as quais agem da mesma forma que a indústria automobilística, pressionando o estado na intenção de obterem maiores isenções fiscais. Além disso, o autor ressalta que elas promoveram uma espécie de hostilidade entre os governos de Minas Gerais e do Rio de Janeiro, que buscava atrair para si tais empresas, gerando uma série de desavenças interestaduais.

Uma instância responsável pela resolução dos conflitos entre os estados é o Conselho Nacional de Política Fazendária (Confaz), que não tem junto aos estados muita representação, pois estes frequentemente acabam burlando as regras impostas por este órgão, criando suas próprias normas e provocando conflitos que acabam exigindo uma intervenção jurídica. É preciso considerar, entretanto, as regras inerentes ao Confaz, que são decisões tomadas por unanimidade dos membros do conselho. Ou seja, se um estado tem oposição a determinado benefício concedido a outro, tal benefício não se aplica, o que acaba por promover uma distorção deste princípio da conformidade entre os estados: em alguns casos - como afirma Arbix (2002) -, os entes subnacionais utilizam-se da regra da unanimidade para barganhar algum benefício em troca da aprovação de determinado incentivo fiscal ao estado pleiteante.

Diante da não aceitação do Confaz como arena privilegiada para a solução de conflitos federativos, surge o modelo de competição não cooperativa, que maximiza práticas individualistas por parte dos estados, mesmo desrespeitando o Confaz e suas regras ou ainda desvirtuando estas regras, com o objetivo de que as mesmas Ihes tragam benefícios imediatos. A partir de estudos de casos $^{4}$, evidencia-se que esta "guerra" causa danos à nação como um todo, porque, primeiramente, ela é um incentivo estadual e não federal, ou seja, os grandes vencedores com esta prática 4. Ver Octávio Dulci (2002) e Ricardo Varsano (1997). são os estados e não a União. Ademais, os ganhos difusos promovem irremediavelmente perdas para o conjunto da federação, acabando por gerar um jogo competitivo de soma zero. O ponto central para a argumentação deletéria da guerra fiscal reside no fato de que a utilização de recursos públicos estaduais para a promoção de 
um deslocamento industrial, acaba gerando um desenvolvimento regional tortuoso, onde toda a federação sai perdedora.

Como ressalta Ricardo Varsano (1997), a dinâmica do desenvolvimento apresenta uma natureza nacional e, por este motivo, deve ser perseguida sob a coordenação do governo central. Há um dado adicional também relevante: quando os estados tentam assumir o encargo para atração de empreendimentos industriais, os resultados não são aqueles esperados. Os estados que conseguem a instalação de grandes empreendimentos são geralmente os estados fortes, com grande capacidade técnica, financeira e burocrática. Além disso, ao conceder incentivos fiscais, serviços públicos básicos para a população - como saúde, educação, saúde pública etc. - são afetados por falta de recursos. Um terceiro elemento merece destaque: na hasta travada entre os estados para a atração de investimentos, há uma oscilação nas contas públicas estaduais significativa. Como destaca Rui B. Affonso (1995), em alguns casos, o estado até já foi escolhido para a instalação da empresa, mas a mesma se utiliza do leilão como artifício para forçar a concessão de vantagens extras.

Alguns estados reconhecem os efeitos nocivos desta prática, mas não se posicionam para interrompê-la porque ou já participam do programa de incentivos ou ainda por planejarem realizar, no futuro, concessões. Neste esquema permeado pela guerra fiscal, os governadores têm participação essencial, tanto para a valorização dos territórios que representam, quanto para maximizar projetos políticos individuais, os quais poderão ser utilizados em arenas eleitorais mais amplas, a longo prazo. Como ressalta Varsano:

\footnotetext{
O governador de um estado, como homem público que é, está certamente empenhado em atender aos objetivos maiores da nação. Mas, até mesmo por dever do ofício, coloca os de seu estado acima daqueles e, no caso do conflito de interesse, certamente defenderá os de sua unidade, tendo como bandeira a autonomia dos entes federados. Ademais, preocupa-se também - ninguém é de ferro - com sua carreira política. Se a concessão de incentivos, ao menos na sua visão, traz benefícios para seu estado e, além disso, gera bons dividendos para seu projeto político pessoal, junta-se o útil ao agradável. Ele fatalmente os concederá, a despeito dos interesses nacionais, ainda mais quando estes se manifestam de forma difusa, como, por exemplo, eficiência econômica (Varsano, 1997: 12).
}

Algumas tentativas de extinguir a guerra fiscal aconteceram desde a revisão constitucional de 1993, que estabeleceu mecanismos com o objetivo de promover mu- 
danças no ICMS, buscando uniformizar as alíquotas diferenciadas. No entanto, tais tentativas foram sufocadas pelo discurso regionalista, o qual corrobora o preceito de que na ausência de políticas de desenvolvimento, a guerra fiscal é o único meio de promoção de um dinamismo econômico. Todavia, se invertermos o ângulo de observação, podemos mesmo dizer que, se é vantagem para o governador, a médio prazo o investimento industrial por meio de renúncia fiscal (já que não existe nenhum freio para isso), como ele apoiará projetos de desenvolvimento oriundos do Executivo, que talvez não tenham os mesmos benefícios a curto e médio prazo? Portanto, afirmar que a guerra fiscal é um fenômeno que atua onde o Estado não intervém de maneira extensiva, é fazer mea-culpa para justificar a ausência de análises mais amplas, pois a prática da isenção fiscal é o mecanismo mais vantajoso a curto e médio prazo, e atenua, desta maneira, qualquer estratégia de desenvolvimento que emane do topo da escala de poder, ou seja, do Executivo Federal.

No entanto, podemos mesmo assumir que no caso das renúncias fiscais reina, de maneira quase plena, o homo economicus. Não existe um só estado que não pratique a guerra, o que reafirma a máxima de que, mesmo a considerando como prática deletéria, agem porque sabem que outros farão o mesmo, num claro movimento de estarem todos, individualmente, trabalhando em nome de seus interesses particulares. Como salienta Varsano:

\begin{abstract}
Nenhum governador é desinformado e, entre eles, é raríssimo um caso de miopia econômica. Todos sabem, no limite, os efeitos da guerra fiscal do ICMS. Mas sabem também que, enquanto o limite não for atingido, há ganhos a serem obtidos fazendo a guerra fiscal. Nessa questão, existem claramente erros de sinalização econômica, que criam divergências entre os objetivos nacionais e estaduais e entre a melhor estratégia de desenvolvimento a curto e a longo prazo (Varsano, 1997: 14).
\end{abstract}

Portanto, retomamos os princípios weberianos que ressaltam que quando o mercado - e aqui, mais especificamente, o fator econômico - age como esfera autônoma, qualquer laço de cooperação ou de fraternidade é esgarçado. É o que, na verdade, podemos transpor para o fenômeno da guerra fiscal: esta prática tornou-se recorrente, o que impede a prática de laços de cooperação para quem a pratica, afetando, desta maneira, o princípio federativo da mútua cooperação entre os entes federados. Mais do que isso: uma prática aparentemente apenas econômica acaba por exigir medidas eminentemente políticas, para que sejam sanados ou amenizados seus efeitos, a fim de que existam políticas de desenvolvimento regional consistentes, sem incorrer em prejuízos para nenhum ente federado. 
Conclusão:

o "cessar-fogo" ou a prevalência da guerra?

Este trabalho apresentou uma reorganização dos principais conceitos tratados pela teoria da sociologia econômica, que ocupou postos analíticos anteriormente ocupados por economistas, com a predominância do homo economicus. Neste sentido, optamos por trazer um fenômeno aparentemente apenas econômico, como a guerra fiscal, mas demonstrando, contudo, que o mesmo pode ser interpretado através da ótica da sociologia econômica. Apesar de ser um fenômeno desagregador da federação como um todo, a guerra fiscal é praticada não por atores anônimos, mas por agentes socialmente legitimados, que são os governadores de estado, alinhados com grandes empresários. Portanto, se eles - os governadores - declararam por diversas vezes considerar a prática deletéria, então, qual a explicação causal para que continuem procedendo desta maneira? Enfim, qual o papel do Estado nesta prática para o conjunto da federação? O Estado não deveria, pois, atuar de forma a regular estas "situações de mercado"? Não temos a pretensão de resolver todas estas questões aqui, dada a complexidade que as mesmas envolvem, mas objetivamos lançar elementos para a criação de novas agendas de pesquisa, para que os estudiosos se debrucem sobre elas com uma visão sociológica mais apurada, esquecendo-se por alguns instantes, das metodologias puramente economicistas.

Dentre toda a gama de grandes pensadores na linha da sociologia econômica, elegemos Neil Fligstein (2003) para apresentar algumas conclusões sobre a proposta aqui formulada. Tal escolha deve-se ao fato de que - por meio da metáfora "o mercado enquanto política" - o autor oferece uma visão sociológica dos mercados, na qual, por meio da ação dos participantes, tenta criar mundos estáveis e encontrar soluções sociais para a competição, observando a forma como os estados e os mercados estão fortemente interligados. O autor discute como a política intervém nos mercados e, desta maneira, podemos inserir o fenômeno da guerra fiscal, vislumbrando o Estado como o intermediador deste processo.

Esta nova abordagem da sociologia econômica - ou sociologia dos mercados - surgiu como reação à perspectiva econômica neoclássica que argumentava que os mercados selecionavam formas eficazes para maximizar a produtividade; no entanto, através da sociologia econômica verificou-se uma pluralidade de relações sociais que influenciam e estruturam os mercados no interior das sociedades. Assim, Fligstein (2003), instrumentalizado de sua metáfora, oferece uma proposta político-cultural na qual os mercados não são espaços individualistas e sem correlação com o restante da sociedade, ao contrário, são estruturas sociais que surgem e produzem mundos estáveis e são transformados por tais estruturas. 
A metáfora "o mercado enquanto política" expressa duas dimensões. A primeira afirma que os mercados não estão dissociados da política, sendo peças importantes das engrenagens do Estado moderno, o qual, por sua vez, criou condições institucionais para garantir a estabilidade desses mesmos mercados. Uma segunda característica que circunda a metáfora é que a forma como os processos ocorrem no interior do mercado pode refletir dois tipos de projetos políticos: a luta pelo poder no interior das empresas e a luta pelas empresas em dominar os mercados, ambas tônicas do capitalismo. Nas palavras do autor:

A metáfora "mercado enquanto política" serve precisamente como elemento unificador e foca o modo como as estruturas sociais são produzidas com o propósito de controlar a competição e organizar as empresas (Fligstein, 2003: 198).

A ponte que une as duas esferas - Estado e mercado - são as instituições a oferecerem regras compartilhadas, sob a forma de leis ou entendimentos coletivos, mantidos e realimentados através do hábito. Tais acordos podem ser referendados através de um contrato explícito ou implícito, a oferecer concepções de controle e de redução dos custos de transação. As instituições podem agir como intermediadoras no estabelecimento das correlações de competição e colaboração, bem como o modo como as empresas devem ser organizadas para o contexto do mercado, garantindo, paralelamente, a colaboração dos atores econômicos envolvidos.

Uma das maneiras de garantir essa estabilidade dos mercados é construir laços minimamente claros e seguros para que as ações de todos os jogadores sejam previamente calculadas, de modo a que as decisões tomadas visem não somente à satisfação de interesses privados, mas que também considerem as ações coletivas. Neste sentido, com o intuito de garantir a estabilidade dos mercados, há de se ressaltar o papel do Estado, o qual constrói normas seguras, regulamentando, assim, a atuação econômica, com as empresas organizando seus rumos, atuando como agentes que ora competem, ora cooperam para seu benefício pessoal e para o benefício coletivo, como maneira de sobrevivência. O Estado poderia participar efetivamente na construção de mercados estáveis, fornecendo, por exemplo, mecanismos capazes de limitar a competição, aumentando a legitimidade tanto política como econômica. Neste sentido, as propostas sugeridas pela nova sociologia econômica também priorizam os processos políticos, seja na estruturação formal das instituições conduzidas pelo Estado ou mesmo acompanhando a transformação dos mercados.

Em relação à guerra fiscal, uma pergunta merece consideração: por que, afinal, o governo federal não atua no sentido de regulamentar esta competição travada entre os estados da federação, permitindo uma competição menos hobbesiana? O 
conflito é a base de todo sistema federativo, não só no Brasil, mas em diversos países do mundo, porém, a questão é refletirmos sobre um modelo de Estado no qual a competição é, diríamos, mais "organizada", sendo o Estado brasileiro protagonista para "organizar" a competição junto ao conjunto da federação. Lançamos também considerações preliminares de que os governadores de estado se tornaram atores políticos com grande poder dentro de seus territórios (Abrúcio, 2002) e, além disso, fonte de apoio e sustentação política ao governo central. Qual, então, o chefe de Estado que se atreveria a comprar esta briga, com estes chefes territoriais?

No entanto, enquanto não forem estabelecidas regras consistentes, a guerra fiscal continuará a todo vapor. Estas regras consistentes poderiam vir de reformas estruturais e institucionais, como, por exemplo, a definição de um novo sistema tributário, com uma reforma tributária que alterasse a regulamentação do ICMS. Todavia, enquanto o Estado não se manifesta, as leis do mercado ficam à revelia, agindo no sentido de acirrar cada vez mais a competição interestados. A ordem de "cessar-fogo" viria somente através de uma iniciativa emanada do topo da escala de poder. No entanto, parece que o mais viável para não obter inimigos políticos, é deixar que a guerra continue... E...

- Salve-se quem puder!

Abstract: Some themes of an economic nature have also become prominent in areas such as the social sciences, particularly political science, and economic sociology. The objective of this study is to emphasize the role of economic sociology in articulating some analytical sources for themes recurrently present in government agendas, using the phenomenon of fiscal war as the core of our study. Therefore, we aim in this work to discuss fiscal war not as an autonomous phenomenon, belonging to the economic sphere, but as a product of sociological and political interactions on the part of social actors, such as state governors. We use a secondary source bibliography, located in disciplines such as economics, economic sociology, and political science.

Keywords: economic sociology, political science, fiscal war.

\section{Referências}

ABRAMOVAY, Ricardo. Entre Deus e o Diabo: mercados e interação humana nas ciências sociais. Tempo Social, v. 16, n. 2, 2004.

ABRÚCIO, Fernando Luís. A coordenação federativa no Brasil: a experiência do período FHC e os desafios do governo Lula. Revista de Sociologia e Política, "Dossiê Federalismo", n. 24, Jun. 2005. 
- Reforma política e federalismo: desafios para a democratização brasileira. In: BENEVIDES, Maria Victória; KERCHE, Fábio; VANNUCHI, Paulo (Orgs.). Reforma política e cidadania, p. 225-265. São Paulo: Editora Fundação Perseu Abramo, 2003.

—. Os barões da federação: os governadores e a redemocratização brasileira. 2 ed. São Paulo: Hucitec, 2002.

—. Os barões da federação. Lua Nova, n. 33, p.165-183, 1994.

ABRÚCIO, F.; COSTA, V. M. F. Reforma do Estado e o contexto federativo brasileiro. São Paulo: Fundação Konrad Adenauer, 1999.

AFFONSO, R. B. A. A federação no Brasil impasses e perspectivas. In: AFFONSO, R. B. A.; SILVA, P. L. B. A federação em perspectiva. São Paulo: Fundap, 1995.

AMARAL, Roniere Ribeiro. Sobre a sociologia econômica de Max Weber. Revista Sociedade e Estado, v. 17, n. 1, 2002.

ARBIX, Glauco. Políticas do desperdício e assimetria entre público e privado na indústria automobilística. Revista Brasileira de Ciências Sociais, v. 17, n. 48, 2002.

BOURDIEU, Pierre. Les structures sociales de l'économie. Paris: Seuil, 2000.

CARVALHO, Ricardo Ismael. Nordeste: a força da diferença. As dificuldades na cooperação entre os governos estaduais no contexto federativo da Constituição de 1988. Tese (Doutorado em Ciência Política) - Instituto Universitário de Pesquisas do Rio de Janeiro (luperj), Universidade Cândido Mendes, Rio de Janeiro, 2001.

DINIZ, Eli. Globalização, reformas econômicas e elites empresariais. Rio de Janeiro: Fundação Getúlio Vargas, 2000.

DOUGLAS, Mary; NEY, Steven. The strong presence of homo economicus. In: DOUGLAS, Mary; NEY, Steven. Missing persons - a critique of the social sciences. Berkley: University of California Press, 1998.

DULCI, Octávio. Guerra fiscal, desenvolvimento desigual e relações federativas no Brasil. Revista Sociologia e Política, n. 18, Jun. 2002.

FLIGSTEIN, Neil. O mercado enquanto política: uma abordagem político-cultural às instituições de mercado. In: MARQUES, Rafael; PEIXOTO, João (Orgs.). A nova sociologia econômica - uma antologia. Oieiras: Celta Editora, 2003.

GRANOVETTER, Mark. Business groups. In: SWEDBERG, R.; SMELSER, N. J. The handbook of economic sociology, p. 453-475. Princeton; Nova York: Princeton University Press; Russel Sage Foundation, 1994. 
- Economic action and social structure: the problem of embeddedness. American Journal of Sociology, v. 91, p. 481-510, 1985.

- Getting a job: a study of contacts and careers. Harvard: Harvard University Press, 1974.

GRANOVETTER, Mark; SWEDBERG, Richard. The sociology of economic life. San Francisco: Westview Press, 1992.

GRUN, Roberto. A evolução recente do espaço financeiro no Brasil e alguns reflexos na cena política. Dados, v. 17, n. 1, 2004.

—. Modelos de empresa, modelos de mundo: sobre algumas características culturais da nova ordem econômica e da resistência a ela. Revista Brasileira de Ciências Sociais, v. 14, n. 41, 1999.

LEVI, Margareth. A model, a method and a map: rational choice in comparative analysis. In: LICHBACH, M. I.; ZUCKERMAN, A. (Eds.). Comparative politics: rationality, culture and structure. New York: Cambridge University Press, 1997.

—. Uma lógica da mudança institucional. Dados, v. 34, n. 1, 1991.

NORTH, Douglass. Institutions, institutional change and economic performance. Cambridge: Cambridge University Press, 1994.

PRADO, Sérgio; CAVALCANTI, Carlos Eduardo. Aspectos da guerra fiscal no Brasil. São Paulo: Ipea; Fundap, 1998.

RAUD-MATTEDI, C. Análise crítica da sociologia econômica de Mark Granovetter: os limites de uma leitura de mercado em termos de redes e imbricação. Revista Política e Sociedade, v. 4, n. 6, 2005a.

A construção social do mercado em Durkheim e Weber: análise do papel das instituições na sociologia econômica clássica. Revista Brasileira de Ciências Sociais, v. 20, n. 57, p. $127-142,2005$ b.

REIS, Bruno P. W. O mercado e a norma: o Estado moderno e a intervenção pública na economia. Revista Brasileira de Ciências Sociais, v. 18, n. 52, 2003.

REIS, Elisa. Reflexões sobre o homo sociologicus. Revista Brasileira de Ciências Sociais, v. 4, n. 11, 1988.

SWEDBERG, Richard. Sociologia econômica: hoje e amanhã. Tempo Social, v. 16, n. 2, 2004. 
. Max Weber and the idea of economic sociology. New Jersey: Princeton University Press, 1998.

VARSANO, Ricardo. A guerra fiscal do ICMS: quem ganha e quem perde. Planejamento e Políticas Públicas, n. 15, 1997.

WEBER, Max. Economia e sociedade: fundamentos da sociologia compreensiva. Brasília: Editora UnB. v. 1. 1991, [1921].

. Basic concepts of sociology. In: ROTH, G.; WITTICH, C. (Eds.). Economy and society. Berkeley: University of California Press, 1978.

. Critique of stammler. New York: The Free Press, 1977.

WILLIANSON, Oliver. Transaction cost economics and organization theory. In: SWEDBERG, Richard; SMELSER, Neil J. (Orgs.). The handbook of economic sociology. Princeton; New York: Princeton University Press; Russel Sage Foundation, 1994. 